\title{
Artificial-Intelligence: the Scenario of Secularism and Communalism in the Temperaments of Kedarnath
}

\author{
Yameen Khan \\ Department of English and Foreign Languages, Faculty of Engineering and Technology, SRM \\ Institute of Science and Technology, Delhi-NCR Campus, Modinagar, Ghaziabad, UP, India
}

\section{ABSTRACT}

Artificial human brainpower in mechanism programmed to act like humans refers Artificial Intelligence. Human brain also programmed to achieve something. Some people are programmed by their communities and other resources. Same happened in Kedarnath. All over the world, Kedarnath is well known place for Hindus due to religious faith and others for debacle. Men keep inviting the wrath and forget the power of nature due to his selfishness. There is phase description of incidents happed in human life in 'Kedarnath' a famous Indian movie directed by Abhishek Kapoor. The movie was released on December 7, 2018 based on the incident that took place in June 2013 in Kedarnath. Protagonists are Late Sushant Singh Rajput (21 January 1986 - 14 June 2020) and Sara Ali Khan. Role of every player is superb itself. Many characters are affected with artificial intelligence. They try to modify the conditions and incidents of present for future due to self-interest, but couldn't. They don't know the Nature or Supreme Power because everything is programmed if having religious faith. Everything is governed by an invisible power. Men have artificial intelligence by birth and exhibit that according to need. Some higher-people of Kedarnath also affected with. The religious people try to corrupt the hard-disc of nature and humanity due to self-interest. They have double slandered in their character. Universally known, Nature is the representative of Supreme-power. That's why, no-one can challenge. The article is an exhibition of artificial-intelligence in human nature.

KEY WORDS: ARTIFICIAL-INTELLIGENCE, SUPREME-POWER, NATURE, HARD-DISC, PITHOO, KHACHCHAR, DARSHAN, LOVE-JIHAD

\section{INTRODUCTION}

Characters: Kedarnath situated in Rudraprayag district of Uttarakhand in India and sited in the Garhwal range of Himalaya Mountain above 3583 meter from sea level. The river Mandakini also flowing nearby. Due to heavy rainfall there was uncontrolled flood and landslides during 16-17 June, 2013. After all, Unbelievable damage of property and more than 5000 people lost their lives both residents and pilgrims. "Between June 13 and 17, the state of Uttarakhand had received an unusual amount of rainfall. This led to the melting of the Chorabari glacier and the eruption of the Mandakini River" Mostly was

Biosc Biotech Res Comm P-ISSN: 0974-6455 E-ISSN: 2321-4007

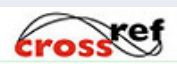

Identifiers and Pagination

Year: 2021 Vol: 14 No (8) Special Issue

Pages: 214-217

This is an open access article under Creative

Commons License Attribn 4.0 Intl (CC-BY). DOI: $h t t p: / / d x . d o i . o r g / 10.21786 / b b r c / 14.8 .50$ ruined exclusive 8th century old temple. It may be a miracle. A huge stone was flown with flood and stopped just behind the temple, the flow of water diverted; there was no damage in temple.

Artificial intelligence is a branch of Computer Science Engineering and properly running in the world. Technically, in this arena the computer works like human mind but after programmed. "Artificial intelligence (AI) refers to the simulation of human intelligence in machines that are programmed to think like humans and mimic their actions. The term may also be applied to any machine that exhibits traits associated with a human mind such as learning and problem- solving." This is technical elucidation of Artificial Intelligence. In the light of literature it has some different meaning but not so avert. It is based on human mind and performs like human than obviously clear that human already have Artificial Intelligence in mind and properly use in behaviour. That is human Artificial Intelligence. "The simplest human behaviour is ascribed to intelligence,
Article Information

Received: $08^{\text {th }}$ June 2021 ccepted after revision: $24^{\text {th }}$ July 2021 
while even the most complicated insect behaviour is never taken as indication of intelligence." The memory of computer is programmed by human, but the human brain is programmed by God or Universal Power.

\begin{tabular}{|c|c|c|}
\hline S. No. & Artificial Name & Real Name \\
\hline 1 & Mansoor Khan & Sushant Singh Rajput \\
\hline 2 & $\begin{array}{c}\text { Mandakini Mishra } \\
\text { "Mukku" }\end{array}$ & Sara Ali Khan \\
\hline 3 & Brijraj Mishra & Nitish Bharadwaj \\
\hline 4 & Kullu & Nishant Dahiya \\
\hline 5 & Ameena Khan & Alka Amin \\
\hline 6 & Lata Mishra & Sonali Sachdev \\
\hline 7 & Brinda Mishra & Pooja Gor \\
\hline 8 & Bashir & Mir Sarwar \\
\hline 9 & Daddo & Sunita Rajwar \\
\hline 10 & Chief Priest & Arun Bali \\
\hline 11 & Hemchand & Faiz Khan \\
\hline 12 & Himalaya Tyagi & Sharad Vyas \\
\hline 13 & Tarang & Priyadarshan \\
\hline 14 & Helicopter Co-Pilot & Hitesh Bhardwaj \\
\hline 15 & Uncle at party & Lalu Makhija \\
\hline
\end{tabular}

There are unlimited ideas, imaginations, methods etc. stored in brain and activated accordingly, may be used optimistically or pessimistically. According to literature, the place where these ideas are stored called Spiritus Mundi. "Spiritus Mundi According to William Butler Yeats, a universal memory and a muse of sorts that provides inspiration to the poet or writer. To Yeats, Spiritus Mundi is the source of all images and symbols, a collective unconscious. Spiritus Mundi is difficult to understand, but we will unpack it as best as we can" Human behave in normal way which is acceptable that is intelligence if try to divert something after knowing everything that is Artificial Intelligence. That is used in Kedarnath at large scale.

The movie surrounds mainly two aspects. One is the love between Mansoor and Mukku another is disaster. The protagonist is a pithoo who port the luggage and pilgrims on Khachchar or on his back also from bottom to top and top to bottom. Distance is $16 \mathrm{~km}$; really it's a hard work. Mostly Pithoos are Muslims. Mansoor thinks his work is service of God that's why he charges small amount. Money doesn't preferred by him, and feel better to serve the pilgrims. "Mahabani karke kuchh kamake ghar bhi leana, sab yatrio pe lotake mat ajana" (Kedarnath) Old pilgrims are helped by him to Darshan habitually. It's a human nature that became acquainted with around areas or things he lives. The same with him, he knows everything about Kedarnath after being a Muslim and living here by birth. The protagonist first time faces Artificial Intelligence with an old female pilgrim. She knows that mostly pithoos are Muslims in
Kedarnath but demands a pithoo belong to her religion. There are different images of Muslims in the minds of some non-Muslims who don't know the reality. She was not agreeing to go with him but after all complete her pilgrimage due to Artificial Intelligence of Mansoor Khan with the help of Rushtam name of his Khachchar. "Okay, ride on Rushtam neither read Quran nor Arti" (Kedarnath)

Single child have extraordinary observation through parents. Naturally, single child and single parent become more valuable for each other and same with him. He was attracted by Mukku after long efforts and became physical incidentally. There are many people who confess for others. After Mukku's revolt, he confesses in front of her father but punished badly by Kullu's men. This is the genuine scene of the movie. Hero is beaten and no fights like Indian traditional heroes. Problems will create against entire community living in Kedarnath. He denies to meeting her because no one accept this relationship due to communalism. There are many examples in India in present scenario that Hindu weds Muslim and Muslim weds Hindu and living happily without fear.

There is a long list but no need to mention their names and address because entire India know this. One thing is common among those people, mostly are rich. It's a universal truth that Money is second god. All social rules established for common people not for rich. That's why Mansoor can't afford this relationship. Common Muslims accused with Love-Jihad and rich Muslims awarded in society. Same in other side, Common Hindu discard by particular community and rich are awarded. The rich people know that how to handle the people with artificial intelligence. Inter-religion-marriage become a national issue and even inter caste marriage is not accepted in common people of both sides.

Due to artificial intelligence, Lots of people never became in touch or communicate with but having special thoughts about some communities. Already, minds have been programmed. Some people became aggressive when conversation started about. There are many open statements given about them through electronic and print media that they are involve in Anti-National activities; love-jihad, increasing population, etc. they are aware about the reality of these propagandas. "This propaganda is followed by actual violence against Muslims-lynching, molestation, and even rape. Despite this hostile anti-Muslim attitude, Muslim communities do not get involved in any counter mobilization." If any people involved in such activities he not belong to any community or religion. The reality is that some people are using to Hindus at the name of religion and same with Muslims. Both communities are emotionally blackmailed at mass level. Artificial Intelligence is used against the people at large scale. There are lots of Hindus having real status of Muslims and live together happily even involve in religious occasions. Hindu-Muslim factor is a running fashion in present time in India. Mostly parts are affected directly or indirectly with it. 
Lots of movies, dramas, serials, short films, clips etc. which directly or indirectly exhibit communal activities as in Kedarnath. No doubt, these are the mirrors of society but using sharply with artificial intelligence. How many people read History, National or International? But in present scenario history is exhibited in parts with communalism and secularism also by movies or serials with artificial intelligence. An example caught in Kedarnath. Kullu don't like, that Mansoor Khan came in the temple premise and directly refuse him. But he came as usual and rings the bell due to secularism. It means other Muslim pithoos are not permitted to enter the premise. Mansoor Khan does argue against illegal construction and other unnatural activities in meeting, suddenly got answer from Kullu;

"Tum kahan se aaye hamare beech"

"Ab Mansoor Khan hame batayega ki hame hamare Bhagwan se kab aur kaise milna hai”(Kedarnath)

According to him Muslims are not resident of Kedarnath. Although he knows reality that mostly pithoos are Muslims and living together from centuries but he tries to impress his community through artificial intelligence but finally got a big answer from Mansoor khan;

"Beech! Ham to hamesha se hain yahan aapke sath" "Beech me kahan se Aaye"

"Kandho par bitha kar teerth karaya hai" "Om Namah Shiway ke hullare lagaye hain"

"Shradha me unki shamil hua hain" "Pushte hamari sewa karti aai hain"

"Teerath hamari ragon me hai" "Hame kaise bahar nikalenge aap"

"Sabse pahle Amarnath ki gufa Buta Malik ko Dikhai di thi"

"Aaj bhi unke ghar chadawa jata hai, harsal”(Kedarnath)

This is a universal truth that one of three reasons is responsible behind every encounter named money, women and land. Unfortunately all reasons are active in Kedarnath with proper use of artificial intelligence. Kullu wants to achieve directly a beautiful girl through marriage and indirectly her father's property, but this world is running through the law of Nature or God. He engaged with elder sister from childhood but later interested in younger because she is more beautiful. Astonished! Allotment is done by her father. Suppose; she is an objective not a human. More surprise is that everything is running near Lord Shiva. One more thing, he knows that she became engaged with Mansoor Khan even got married with her. This is the biggest example of voracity with a proper use of artificial intelligence. Due to power, one can control self-body or someone but the spirit, emotions, feelings, thoughts are uncontrolled.
Mostly, heart is not controlled by self or others. There are lots of examples in past, present and may be in future. The game started between Mukku and Kullu named mangetar - mangetar (fiancee - fiancee). Five candidates come after engagement and want to marry with her. Artificial intelligence was used with those people and sixth was Mansoor Khan. He was observed as a next target.

"Rambada tak chaloge, jante ho na hame" She caught his hand,

"Pura Goricund tak ka tax bhar denge, utar Rambada me dena, tumhe kiya, Chalo..."

"Kaise mard ho aurto ki madad ka riwaz nahi hai tumhare yahan"

\section{"Facebook pe ho"}

"Pata hai meri badi ma kahti thi jab koi khobsoorat ghatna ghatti hai to rooh bahar rnikalkar aajati hai ankho me, suna hai kabhi"

"Sharm nahi aati tumhe, waise koi ladki dekh rahi hai ye nahi k palat kar dekhlen" (Kedarnath)

If we start the mission with a perfect plan obviously the target achieved easily but results depend on assignments. These are the dialogues in front of unknown guy. Programme was preplanned but finally falls in love unwillingly. He is not interested but no one can hide the fragrance of love and finally surrender in front of heart. This is the turning point of life. A free mind person wants to live free everywhere and same with her. She is liar and tongue is uncontrolled, during a match between India and Pakistan "Teri ma ki......" She is brave also and cut her thumb and later veins. After death of lover, she listen his favorite song on redio from a movie named 'Wo Kaun Thi'

"Lag ja gale ke fir ye hasin rat ho na ho, Shayad phir is janam me mulakat ho na ho........."

It's not a business deal. It's a relation of seven times birth according to Hindu mythology. Brijraj Mishra father of Mukku a well know person and business man agreed to change her younger daughter instead of elder daughter to marry with Kullu. How it's possible. He also used artificial intelligence against Kullu and her daughter. Mother of Man soor Khan, when does she know about beloved of her son became afraid "sab keliye musibat ho jayegi" Due to communalism the entire people will be punished. Artificial intelligence also used by her, "jalade mujhe ya bhulade use" Because, being a mother she doesn't want to lose her only son at any cost. Noone can understand the play of God. That's why she couldn't use artificial intelligence against son; that was the demand of that time. After all, the son was lost in flood due to secularism in the service of those people affected with communalism. 


\section{CONCLUSION}

A proper use of artificial intelligence is very easy to observe among the characters of Kedarnath in the scenario of communalism and secularism. Movies are the mirror of society and aware through the incidents happen, but some time people avoid the message and indulge in adverse situations. The Nature and Society never tolerate unnatural activities and things. Finally, the human never changes the law of Nature and Society through Artificial Intelligence.

\section{REFERENCES}

Bowman, Wayne D. (2006) "Whynarrative? Why now?" Research Studies in Music Education 27.1: 5-20

Dhingra, Vaishali, NehaAnand and Manish Dhingra, (2020) "DISCOVERING THE CHRONICLE OF INTER CASTE MARRIAGE: SHACKLE OF NARROW MINDEDNESS." Pal Arch's Journal of Archaeology of Egypt/Egyptology 17.6: $10176-10188$

https://indianexpress.com, Updated: December 7, 2018 2:04:07 pm https://www.britannica.com https://www.india.com, Updated: July 13, 2017 5:55 pm

https://www.investopedia.com

Jones, Stephen H., et al, (2019) "That's how Muslims are required to view the world': Race, culture and belief in non-Muslims' descriptions of Islam and science" The Sociological Review 67.1: 161-177

Niemeier, Susanne. (2008) "To be in control: kind-hearted and cool-headed. The head-heart dichotomy in English" Culture, body, and language: Conceptualizations of internal body organs across cultures and languages: 349-372

Nussbaum, Martha, (2000) "Women's capabilities and social justice" Journal of human development 1.2: 219247

Rautela, Piyoosh. (2013) "Lessons learnt from the deluge of Kedarnath, Uttarakhand, India." Asian Journal of Environment and Disaster Management 5.2: 43-51

Rich, Elaine. (1985) "Artificial intelligence and the humanities" Computers and the Humanities: 117-122 